\title{
Potential of Magnesium Chloride for Nutrient Rejection in Forward Osmosis
}

\author{
Yatnanta Padma Devia1,2*, Tsuyoshi Imai1, Takaya Higuchi'1, Ariyo Kanno ${ }^{3}$, \\ Koichi Yamamoto 3 , Masahiko Sekine ${ }^{3}$, Tuan Van Le ${ }^{4}$ \\ ${ }^{1}$ Division of Environmental Science and Engineering, Graduate School of Science and Engineering, Yamaguchi \\ University, Ube-shi, Japan \\ ${ }^{2}$ Department of Civil Engineering, Brawijaya University, Malang, Indonesia \\ ${ }^{3}$ Division of Civil and Environmental Engineering, Graduate School of Science and Engineering, Yamaguchi \\ University, Ube-shi, Japan \\ ${ }^{4}$ Department of Environmental Science, Hue University of Science, Hue City, Vietnam \\ Email: ”yatnanta@yahoo.com, imai@yamaguchi-u.ac.jp
}

Received 3 June 2015; accepted 10 July 2015; published 13 July 2015

Copyright (C) 2015 by authors and Scientific Research Publishing Inc.

This work is licensed under the Creative Commons Attribution International License (CC BY).

http://creativecommons.org/licenses/by/4.0/

(c) (i) Open Access

\begin{abstract}
Wastewater may contain high levels of the nutrients: nitrogen and phosphorus. Excessive release of nutrients to the environment can cause severe environmental problem such as eutrophication leading to algal blooms, oxygen deficiency, and fish kills. The forward osmosis (FO) could be a choice of treatment. FO process presents the results of using four kinds of variation in concentration of magnesium chloride $\left(\mathrm{MgCl}_{2}\right)$ as draw solution and the two kinds of commercial membranes for nutrient rejection in the same cross flow velocity at $0.25 \mathrm{~m} / \mathrm{s}$ and temperature at $25^{\circ} \mathrm{C}$. $\mathrm{Nu}$ trients consisting of nitrogen (nitrite, nitrate, and ammonium) and phosphorus (phosphate) in feed solution were successfully rejected with an efficiency of mostly more $95 \%$. The water flux in membrane HTI-NW achieved lower $7.55-9.61 \mathrm{~L} / \mathrm{m}^{2} \cdot \mathrm{hr}$ than in membrane HTI-ES that exceeds until $13.58-15.10 \mathrm{~L} / \mathrm{m}^{2} \cdot \mathrm{hr}$. The reverse solute in membrane HTI-NW is seemly constant along all concentration of $\mathrm{DS}_{\mathrm{MgCl}_{2}}$ that the chloride diffusion is slightly higher than magnesium. In membrane HTI-ES, the reverse solute of chloride was almost three times than that of magnesium. The concentration of $\mathrm{MgCl}_{2}$ plays a significant role in rejecting nutrients by the Donnan's potential and the diffusion constant in low and high concentration of DS, respectively.
\end{abstract}

\section{Keywords}

Forward Osmosis, Magnesium Chloride, Nutrient

\footnotetext{
*Corresponding author.
}

How to cite this paper: Devia, Y.P., Imai, T., Higuchi, T., Kanno, A., Yamamoto, K., Sekine, M. and Le, T.V. (2015) Potential of Magnesium Chloride for Nutrient Rejection in Forward Osmosis. Journal of Water Resource and Protection, 7, 730-740. 


\section{Introduction}

Forward osmosis (FO) membrane technology research has grown remarkably in the last decade. In FO, solutions of lower and higher osmotic pressure potential are named feed solution (FS) and draw solution (DS), respectively. Natural osmotic difference drives water from FS to DS through a membrane. FO uses a semi-permeable membrane to separate water from feed solute effectively. A selectively or semi-permeable membrane allows passage of water, but rejects solute molecules or ions [1]. The DS and membrane should be optimized to increase the efficiency and to decrease concentration polarization [2]. The concentration polarization is caused by the concentration difference between the FS and DS troughs across an FO membrane [3]. The concentration polarization arises as the water flux in FO has an opposite direction to the reverse solute flux [4]. According to Ge et al. (2013), the resolution of high efficiency FO membranes and suitable DS, related to the molecular solution, is required [5].

This research utilized $\mathrm{MgCl}_{2}$ as a molecular solution DS for the following reasons. $\mathrm{MgCl}_{2}$ has a relatively high osmotic pressure that has been tested for the prediction of the properties of solutions over a wide range of concentrations and temperatures [1]. Achilli et al. (2010), in their experiments, concluded that $\mathrm{MgCl}_{2}$ may be the best DS for most water and wastewater applications, and suggested that it warranted further investigation to be used in environmental engineering applications [6]. The role of $\mathrm{MgCl}_{2}$ in the $\mathrm{FO}$ process of wastewater treatment application, especially for nutrient from secondary treated effluent and its rejection mechanism, has been rarely investigated. Excessive release of nutrient to the environment can cause severe environmental problem such as eutrophication leading to algal blooms, oxygen deficiency, and fish kills [7]. Some previous experiments have been conducted for membrane test by using $\mathrm{MgCl}_{2}$ as DS and deionized (DI) water as FS [8]-[11]. According to Lay et al. (2010) and Lee et al. (2010) multivalent ions (e.g. $\mathrm{Ca}^{2+}$ and $\mathrm{Mg}^{2+}$ ) solution with lower diffusion coefficients may be preferable in some specific applications in which high removal is desired [12] [13].

Mostly the previous studies used sodium chloride ( $\mathrm{NaCl}$ ) and sea salt as DS. A study by Cath et al. (2010), investigating the rejection of ammonia and nitrate by FO membrane, showed that rejections of $74 \%$ and $78 \%$, respectively, were achieved with sea salt as DS and secondary effluent as FS [14]. In their study, combined FO and RO membrane was also used that resulted in higher rejection of $94 \%$ for ammonia and $97 \%$ for nitrate. Holloway et al. (2007) investigated the rejection of ammonia, total kjeldahl nitrogen (TKN), and orthophosphate by a cellulose triacetate membrane that uses $\mathrm{NaCl}$ as DS [15]. Their study indicated that $82.9 \%, 91.6 \%$ and $99.8 \%$ rejection of ammonia, TKN, and orthophosphate were achieved, respectively, for FO-treated centrate in the increasing FS concentration. Xue et al. (2015) investigated enriching nitrogen and phosphorus with synthetic seawater as DS [16]. They concluded, at water reduction 50\%, dissolved organic carbon and phosphate were 2.3-fold concentrated, ammonia 2.1-fold concentrated, while nitrite and nitrate were 1.9-fold and 1.3-fold, respectively. Retention of ammonia by cellulose triacetate (CTA) membrane was approximately $90 \%$ and negative retention by thin film composite (TFC) membrane in active layer-feed solution orientation.

Based on the aforementioned reasons, this study aims to investigate $\mathrm{MgCl}_{2}$ potential for nutrient rejection using the FO process. This study established an understanding of the mechanism and relation of $\mathrm{MgCl}_{2}$ as DS, nutrient on FS and membrane to provide further insight into the rejection of nutrients by the FO process. This can be potentially useful for future application in wastewater treatment plants.

\section{Material and Methods}

\subsection{Feed and Draw Solution}

A sample of secondary treated effluent from the Eastern Municipal Wastewater Treatment Plant in Ube City, Yamaguchi, Japan was collected and its nutrient concentration, i.e., nitrogen content (nitrite, nitrate, and ammonium) and phosphorus (phosphate) content, was measured as shown in Table 1.

In our FO process, an artificial secondary treated effluent was used as FS, which was prepared by referring to the actual concentrations of secondary treated effluent. The sources of nitrite, nitrate, ammonium, and phosphate were $0.03 \mathrm{mM}$ sodium nitrite $\left(\mathrm{NaNO}_{2}\right), 2.8 \mathrm{mM}$ potassium nitrate $\left(\mathrm{KNO}_{3}\right), 0.85 \mathrm{mM}$ ammonium chloride $\left(\mathrm{NH}_{4} \mathrm{Cl}\right)$, and $0.3 \mathrm{mM}$ potassium hydrogen phosphate $\left(\mathrm{KH}_{2} \mathrm{PO}_{4}\right)$, respectively. The DS was prepared by dissolving magnesium chloride hexahydrate $\left(\mathrm{MgCl}_{2} \cdot 6 \mathrm{H}_{2} \mathrm{O}\right)$ in DI water (SA 2100E Eyela Japan) at concentrations of $0.5 \mathrm{M}, 1 \mathrm{M}, 1.5 \mathrm{M}$, and $2 \mathrm{M}$.

Standard solution was prepared in the desired concentration range using stock standard and dilute DI water. 
Table 1. Concentration of nutrients in an actual secondary treated effluent sample.

\begin{tabular}{cc}
\hline Nutrient & Concentration $(\mathrm{mg} / \mathrm{L})$ \\
Nitrogen & 0.1 \\
Nitrite $\left(\mathrm{NO}_{2}-\mathrm{N}\right)$ & 11.4 \\
Nitrate $\left(\mathrm{NO}_{3}-\mathrm{N}\right)$ & 3.4 \\
Ammonium $\left(\mathrm{NH}_{4}-\mathrm{N}\right)$ & \\
Phosphorus & 2.7 \\
\hline
\end{tabular}

Samples were diluted to facilitate the measurement within the standard calibration range. The nitrogen $\left(\mathrm{NO}_{2}-\mathrm{N}\right.$, $\mathrm{NO}_{3}-\mathrm{N}$, and $\left.\mathrm{NH}_{4}-\mathrm{N}\right)$ and phosphorus $\left(\mathrm{PO}_{4}-\mathrm{P}\right)$ contents were determined by referring to the standard methods [17] using a UV-Vis spectrophotometer principle (Hitachi U-1800). The viscosity of FS and DS was measured by a viscometer (TVC-5 Toki Sangyo Japan).

\subsection{Membrane}

Two of the FO membranes used in this study were acquired from Hydration Technology Innovations (HTI, Albany, OR). The membrane chemistry are proprietary, though it is believed that the membranes were asymmetric CTA nonwoven support layer (HTI-NW) and TFC with embedded polyester screen support (HTI-ES), and negatively charge surface [4]. The surface-active layer, support layer, and cross section of the membranes were observed using Scanning Electron Microscopy (SEM) (Keyence VE 8800).

\subsection{Forward Osmosis Cross Flow Set-Up}

The membrane was installed in a membrane module consisting of two rectangular sides with the dimensions 135 $\mathrm{mm}$ long, $90 \mathrm{~mm}$ wide, and $4 \mathrm{~mm}$ deep and an effective membrane area of $0.012 \mathrm{~m}^{2}$ that permitted the FS and DS to flow to the membrane. In FO application mode, the active and support layers of the membrane were facing the FS and DS, respectively [5]. Two peristaltic pumps equipped with a speed controller (Eyela, RP-2100) were used to recirculate the FS and DS. Cross flow velocities of $0.25 \mathrm{~m} / \mathrm{s}$ were applied. Two proportional flasks were used to store $3.5 \mathrm{~L}$ artificial FS and $1 \mathrm{~L}$ DS. The weight of both of these flasks and their contents were measured (PB5001-5 Mettler Toledo USA) at initial and final stages of the FO process to calculate reverse solute flux. In the reverse solute flux calculation, not only initial and final volume of FS but also their conductivities (Horiba ES-14) were measured. The permeate water from FS through the membrane into the DS was allowed to overflow into a beaker placed on a balance meter (PJ3000 Mettler-Toledo USA). The change in weight on the balance was recorded for the measurement of the water flux through the membrane. The FO cross flow apparatus was completed with conductivity meter and balance meter. This apparatus showed in Figure 1. A single cross flow experiment was carried out in 8 hours [15] [18]. During the experiment, the room temperature was maintained at $25^{\circ} \mathrm{C} \pm 1.0^{\circ} \mathrm{C}$. The $\mathrm{pH}$ of FS and DS were $7.2 \pm 0.2$ and $6.3 \pm 0.2$, respectively. The temperature and $\mathrm{pH}$ were monitored intermittently with a thermometer and $\mathrm{pH}$-meter (Horiba D-13), respectively. At the end of the cross-flow process, permeates were collected and analyzed for nitrogen $\left(\mathrm{NO}_{2}-\mathrm{N}, \mathrm{NO}_{3}-\mathrm{N}\right.$, and $\left.\mathrm{NH}_{4}-\mathrm{N}\right)$, and phosphorus $\left(\mathrm{PO}_{4}-\mathrm{P}\right)$ content. The calculation for each rejection was done by subtracting the initial concentration from the final concentration.

\subsection{Nutrient Rejection}

According to McCutcheon et al. (2006) the determination of nutrient rejection in the FS is performed by collecting a sample of diluted DS after a complete FO run [19]. Based on the final concentration of the nutrients in the diluted DS and the initial concentration of the nutrients in the FS before the FO cross flow process, the percentage of rejection, $R$ is calculated [8] [15] [19] [20]. This rejection is showed the actual retention of nutrients that separated/concentrated from permeate water/water recovery. The equation is: 


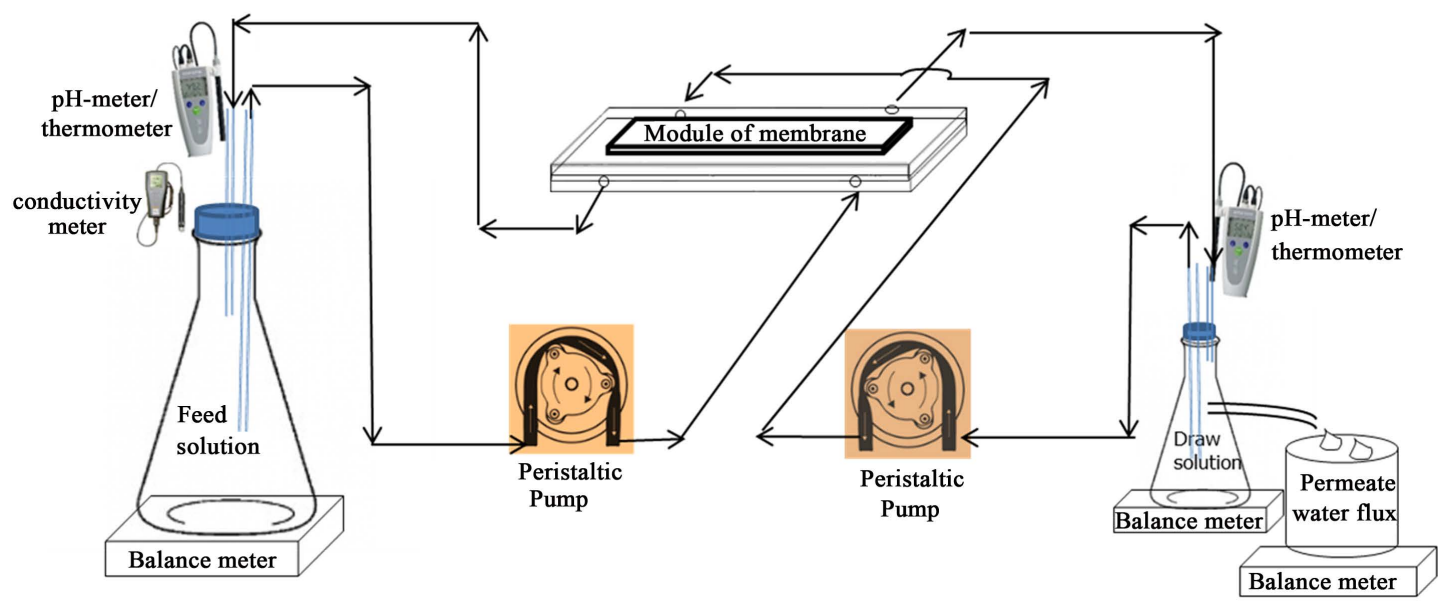

Figure 1. FO cross flow apparatus.

$$
R=100\left(1-\frac{C_{P}}{C_{F}}\right)
$$

where $C_{P}$ and $C_{F}$ are final nutrients concentration in diluted DS after FO process and initial nutrients concentration in FS before FO process, respectively. The nitrogen $\left(\mathrm{NO}_{2}-\mathrm{N}, \mathrm{NO}_{3}-\mathrm{N}\right.$, and $\left.\mathrm{NH}_{4}-\mathrm{N}\right)$, and phosphorus $(\mathrm{PO}-\mathrm{P})$ were determined by referring to the Standard Methods [17] using a UV-Vis spectrophotometer (Hitachi U-1800). All samples were diluted to allow for measurement within the standard calibration range.

\subsection{Water Flux Calculation}

Osmosis leads to water flux from FS to DS across the FO membrane, resulting in an increase in the weight of the DS. The water flux can be calculated using Equation (2), where the change in weight of DS was converted to volume and was divided by the membrane area and time duration.

$$
J_{w}=\frac{W_{e}-W_{0}}{\rho \cdot A_{m} \cdot t}
$$

where $J_{w}$ is the water flux $\left(\mathrm{L} / \mathrm{m}^{2} \cdot \mathrm{hr}\right), W_{e}$ the final weight of DS at the end of the FO process $(\mathrm{g}), W_{0}$ the initial weight of DS (g), $\rho$ density of fluid $\left(\mathrm{kg} / \mathrm{m}^{3}\right), A_{m}$ the membrane area $\left(\mathrm{m}^{2}\right)$, and $t$ the time duration (hour).

The relation between the water flux and osmotic pressure difference is expressed by the following Equation (3):

$$
J_{w}=A \cdot \sigma \cdot \Delta \pi
$$

where $A$ is the water permeability coefficient $\left(\mathrm{L} /\left(\mathrm{m}^{2} \cdot \mathrm{hr} \cdot \mathrm{bar}\right)\right), \sigma$ is the reflection coefficient, and $\Delta \pi$ is the osmotic pressure difference (bar). More specifically, the relation between the osmotic pressure and concentration is explained by the Van't Hoff equation derived from the Morse equation. The osmotic pressure is linearly related to the concentration of the solution that is determined by Equation (4):

$$
\pi=i M R T=i\left(\frac{n}{V}\right) R T
$$

where $\pi$ is the osmotic pressure, $i$ is the Van't Hoff factor, $M$ is the molar concentration of solute particles, which is equal to the ratio of the number of solute moles $(n)$ to the volume of the solution $(V), R$ is the gas constant of $8.3145 \mathrm{~J} \cdot \mathrm{K}^{-1} \cdot \mathrm{mol}^{-1}$, and $T$ is the absolute temperature.

\subsection{Reverse Solute Calculation}

The transported solute from the DS to the FS is named reverse solute. A conductivity meter and a balance meter were used to determine the concentration and volume of FS, respectively, before and after the FO process. Thus, 
the characteristics of the reverse solute were measured. The concentration, which is measured in $\mathrm{mS} / \mathrm{cm}$, was converted to g/L TDS and then divided by the membrane area $\left(\mathrm{m}^{2}\right)$ and the operation time (hours). The reverse solute flux was determined using mass balance calculation as seen on Equation (5):

$$
J_{s}=\frac{C_{t} V_{t}-C_{0} V_{0}}{A_{m} \cdot t}
$$

where $J_{s}$ is the reverse solute flux $\left(\mathrm{g} / \mathrm{m}^{2} \cdot \mathrm{hr}\right) ; C_{0}$ and $C_{t}$ are the concentration of solute in the FS before and after the FO process, respectively; $V_{0}$ and $V_{t}$ are the volume of the FS before and after the FO process, respectively.

To investigate each diffusion constant of ion $\mathrm{Mg}^{2+}$ and $\mathrm{Cl}^{-}$, analysis of these ions were conducted using Optical Emission Spectrometry Inductively Coupled Plasma (OES ICP Optima 3300) for $\mathrm{Mg}^{2+}$ and argentometric method for $\mathrm{Cl}^{-}$.

The reverse solute flux was affected by concentration difference between FS and DS. This phenomenon can be described by Fick's Law in Equation (6) [6]:

$$
J_{s}=B \Delta C
$$

where $B$ is the solute permeability coefficient $\left(\mathrm{L} / \mathrm{m}^{2} \cdot \mathrm{hr}\right)$ and $\Delta \mathrm{C}$ is the concentration difference across the membrane $(\mathrm{g} / \mathrm{L})$.

The fluid in different concentration has a viscosity value that is considered to the diffusion constant calculation. The viscosity was measured by a viscometer (TVC-5 Toki Sangyo Japan). The diffusion constant can be expressed as

$$
D=\frac{K_{B} T}{6 \pi r \eta}
$$

where $D$ is the diffusion constant, $K_{B}$ is the Boltzmann constant $\left(1.381 \times 10^{-23} \mathrm{~m}^{2} \cdot \mathrm{kg} / \mathrm{s}^{2} \cdot \mathrm{K}\right), T$ is the absolute temperature, $\eta$ is the viscosity, and $r$ represents the radius of spherical particles.

\section{Result and Discussion}

\subsection{Nutrient Rejection}

To determine whether the induced nutrient rejection by $\mathrm{MgCl}_{2}$ concentration variation was related to the membrane characteristics, data of percentage rejection from the four kinds of variation in concentration of $\mathrm{MgCl}_{2}$ and the two kinds of membranes were generated (Figure 2). When low concentration $0.5 \mathrm{M} \mathrm{MgCl}_{2}$ was used as DS, the rejection of $\mathrm{NO}_{2}, \mathrm{NO}_{3}$, and $\mathrm{PO}_{4}$ in membrane $\mathrm{HTI}-\mathrm{NW}$ were $40.7 \%, 72.9 \%$ and $75.7 \%$, respectively. Whereas, $\mathrm{NH}_{4}$ rejection reached $99.4 \%$. Using membrane HTI-ES, the experiment yielded lower rejections than that of HTI-NW $15.9 \%, 67.7 \%, 44.5 \%$ and $35.8 \%$ of $\mathrm{NO}_{2}, \mathrm{NO}_{3}, \mathrm{PO}_{4}$ and $\mathrm{NH}_{4}$, respectively.

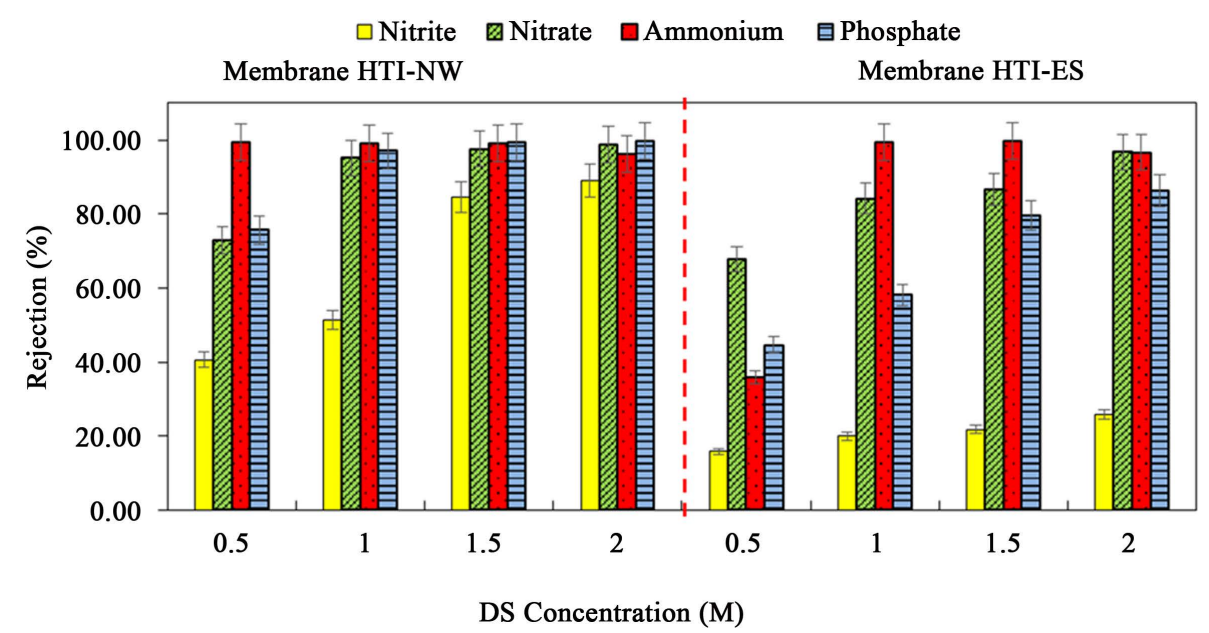

Figure 2. Rejection nutrients based on variation of $\mathrm{DS} \mathrm{MgCl}_{2}$ concentration at $0.5 \mathrm{M}, 1 \mathrm{M}, 1.5 \mathrm{M}$ and $2 \mathrm{M}$ using membrane HTI-NW and HTI-ES. Experiment conditions: cross flow velocity $0.25 \mathrm{~m} / \mathrm{s}$, temperature $25^{\circ} \mathrm{C} \pm 1.0^{\circ} \mathrm{C}$. 
In both of membranes, a low concentration of $\mathrm{MgCl}_{2}$ mostly does not achieve high nutrient rejection except $\mathrm{NH}_{4}^{+}$. The nutrient sources in the $\mathrm{FS}$ and $\mathrm{MgCl}_{2}$ in the DS include polyatomic ions that could dissociate in water. In the ionized water, the monovalent, negatively charge, low molecular weight ions, such as $\mathrm{NO}_{2}^{-}$and $\mathrm{NO}_{3}^{-}$anions, were rejected less than both the $\mathrm{PO}_{4}^{3-}$ anion (multivalent, negatively charge, large molecular weight) and $\mathrm{NH}_{4}^{+}$cation (monovalent, positively charge, and low molecular weight). The presence of multiple ions with varying charges in the FS in which electrical potential at the interfaces of the FS active layer membrane and the DS support layer membrane resulted the adsorption difference of cations and anions. It caused by the Donnan potential. The Donnan potential prevents some of the ions to pass through the FO membrane and is identical to the rejection process.

Furthermore, since the FS does not contain $\mathrm{MgCl}_{2}$, the $\mathrm{Mg}^{2+}$ and $\mathrm{Cl}^{-}$ions try to diffuse along the concentration gradient. To determine the difference diffusion constant between $\mathrm{Mg}^{2+}$ and $\mathrm{Cl}^{-}$ions, it can be calculated by using Equation (7) with $T=25^{\circ} \mathrm{C}$ or $298.15 \mathrm{~K}, \eta=1.0 \mathrm{mPa}$.s or $1.10^{-3} \mathrm{~kg} / \mathrm{m} . \mathrm{s}, 0.5 \mathrm{M} \mathrm{MgCl}_{2}$, and $\mathrm{r}$ as the hydrated ionic radius. The value of the hydrated diameter ion of $\mathrm{Mg}^{2+}$ and $\mathrm{Cl}^{-}$are $0.8 \mathrm{~nm}$ and $0.3 \mathrm{~nm}$, respectively [6]. The respective diffusion constants are $0.55 \times 10^{-9} \mathrm{~m}^{2} / \mathrm{s}$ for $\mathrm{Mg}^{2+}$ ion and $1.5 \times 10^{-9} \mathrm{~m}^{2} / \mathrm{s}$ for $\mathrm{Cl}^{-}$ion. It seems that $\mathrm{Cl}^{-}$ion controlled the diffusion from DS to $\mathrm{FS}$ along concentration gradient. The development of negatively charge in FS force the anion nutrient such as $\mathrm{NO}_{2}^{-}, \mathrm{NO}_{3}^{-}$, and $\mathrm{PO}_{4}^{3-}$ diffuse from $\mathrm{FS}$ to DS to maintain electroneutrality. The smallest anion $\left(\mathrm{NO}_{2}^{-}\right)$easily passed through the membrane from the FS, unlike the other small cation $\left(\mathrm{NH}_{4}^{+}\right)$. Large anions, such as $\mathrm{NO}_{3}^{-}$and $\mathrm{PO}_{4}^{3-}$, do not easily pass through the membrane. On the other hand, the two positively charge hydrogen atoms (electronegativity 2.20) of the water molecule expand and weakly attract the negatively charge ions, such as $\mathrm{NO}_{2}^{-}, \mathrm{NO}_{3}^{-}$, and $\mathrm{PO}_{4}^{3-}$. These all reason explained the low rejection of $\mathrm{NO}_{2}^{-}, \mathrm{NO}_{3}^{-}$, and $\mathrm{PO}_{4}^{3-}$ in low concentration of $\mathrm{MgCl}_{2}$. Conversely, cation $\mathrm{NH}_{4}^{+}$is attracted to the $\mathrm{Cl}^{-}$ion. Moreover, the FS with $3.5 \mathrm{~L}$ water consists of negatively charge oxygen (electronegativity 3.44) resulting from the polar water molecules, which are strongly attracted to positively charge ions, such as $\mathrm{NH}_{4}^{+}$ [21]. This situation explained the high rejection rate of $\mathrm{NH}_{4}^{+}$ion, compared to the other ions in membrane HTI-NW. All these results are consistent with a previous study that concluded the Donnan potential to be the dominant cause of the nutrient rejection mechanism in low concentrations of DS [22].

The rejection increased with increasing concentrations of $\mathrm{MgCl}_{2}$. Thus, by using $2 \mathrm{M} \mathrm{MgCl}_{2}$, the rejection of $\mathrm{NO}_{2}, \mathrm{NO}_{3}, \mathrm{NH}_{4}$, and $\mathrm{PO}_{4}$ in membrane HTI-NW were measured as $89.0 \%, 98.7 \%, 96.2 \%$, and 99.6\%, respectively; whereas in membrane HTI-ES, the nutrient rejections were $25.8 \%, 96.7 \%$, $96.6 \%$, and $86.4 \%$, respectively. A high concentration of the DS will increase the osmotic pressure difference, thereby increasing the driving force, which in turn results in the enhancement of water flux from the FS to DS, and the reverse solute from the DS to FS by the diffusion constant. This diffusion constant is produced by the imbalance in the concentration between the anion and cation nutrient concentrations in the FS and the DS. This affects to electrical double layer into porous membrane. The $\mathrm{Cl}^{-}$ion diffusion controlled into the negatively charge membrane, creating a layer of $\mathrm{Cl}^{-}$into the membrane. The electrostatic repulsion of the negatively charge nutrient ions, $\mathrm{NO}_{2}^{-}, \mathrm{NO}_{3}^{-}$, and $\mathrm{PO}_{4}^{3-}$ anions, increased, and this resulted in an increase in nutrient rejection. The positively charge nutrient ions, $\mathrm{NH}_{4}^{+}$cation, was high rejection in both of the membranes because this cation do not across faster into the DS to balance higher $\mathrm{Cl}^{-}$ion diffusion from DS to FS [23]. The electrical double layer that formed then was compressed, and in an attempt to maintain electroneutrality, it is likely that the paired $\mathrm{Mg}^{2+} \mathrm{ca}-$ tion try diffused to the membrane, causing the entire pore volume to become neutral and the Donnan potential to decrease. Therefore, in high concentrations, the effect of the diffusion constant is more dominant, compared to that Donnan potential, for nutrient rejection.

The commonly used DS in FO are $\mathrm{NaCl}$ and seawater. The diameter of the hydrated $\mathrm{Na}^{+}$ion is $0.45 \mathrm{~nm}$, resulting in a higher diffusion constant than $\mathrm{Mg}^{2+}$. In comparison, $\mathrm{Na}^{+}$and $\mathrm{Cl}^{-}$ions have very similar high diffusion constants, because of their some similar hydrated diameters or nearly equimolar [24]. Therefore, difference in diffusion constants between both of them is small, causing varied performance of anion or cation rejection. The seawater seemly has more various diffusion constant due to the complexity of ions. It worth noting that in this study, the $\mathrm{Cl}^{-}$ion seemly higher diffuse than that of $\mathrm{Mg}^{2+}$ ion due to an indication of high $\mathrm{NH}_{4}{ }^{+}$cation rejection. The further explanation of individual $\mathrm{Mg}^{2+}$ and $\mathrm{Cl}^{-}$ions was explained in sub chapter 3.2.

The percentage of rejection varies for membrane HTI-NW and HTI-ES, and the difference between the two could be explained by membrane morphologies. The surface of the active layer, support layer, and a cross-sectional area of the membrane HTI-NW are shown in Figures 3(a)-(c), respectively, and those for membrane HTI-ES are shown in Figures 4(a)-(c), with the help of SEM test. The active layer membrane HTI-NW 


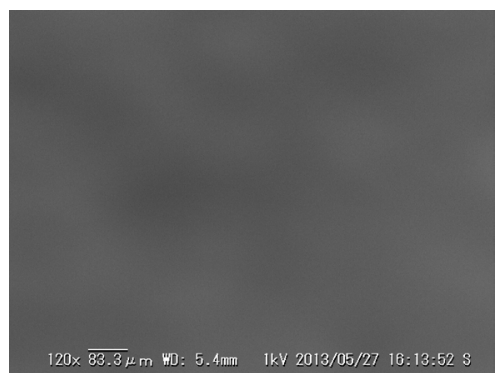

(a)

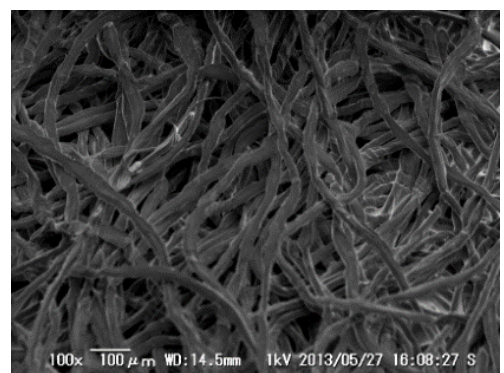

(b)

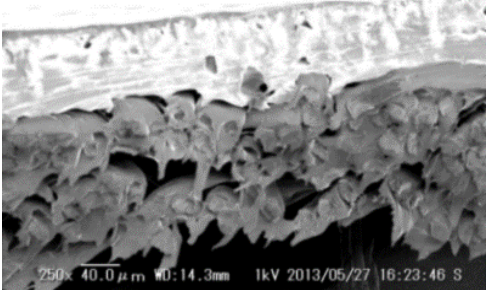

(c)

Figure 3. SEM images of the HTI-NW membrane produced by HTI: (a) Surface layer of active layer $( \pm 100 \times)$; (b) Surface layer of support layer $(100 \times)$; (c) Cross-sectional area $( \pm 200 \times)$.

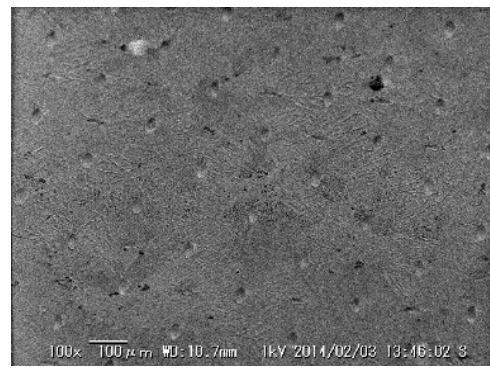

(a)

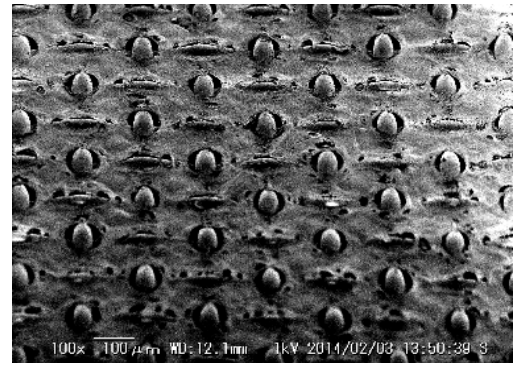

(b)

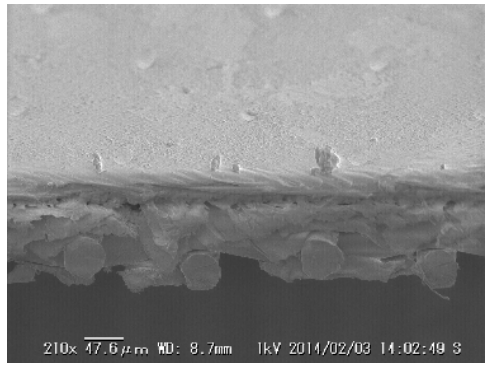

(c)

Figure 4. SEM images of the HTI-ES membrane by HTI: (a) Surface layer of active layer $( \pm 100 \times)$; (b) Surface layer of support layer (100×); (c) Cross-sectional area $( \pm 200 \times)$.

appears smoother and less porous (Figure 3(a)) resulting in a good nutrient rejection efficiency (Figure 2) than that of membrane HTI-ES (Figure 4(a)).

\subsection{Water Flux and Reverse Solute}

To determine whether the $\mathrm{MgCl}_{2}$ concentration and membrane morphologies were related to water flux and reverse solute, the data of Figure 5 were generated. When the experiment using the same FS concentration and higher DS concentration, the concentration difference between FS and DS increases, the difference in osmotic pressure increases, and generates a higher water flux through the membrane due to the driving force that was verified by Equation (3). Moreover, the importance of $\mathrm{MgCl}_{2}$ in driving the water flux was confirmed by Equation (4), according to which a DS with a higher Van't Hoff factor could produce a higher osmotic pressure. Thus, the osmotic pressure difference would be increased, and this would result in an increase in the water flux. For example, $\mathrm{MgCl}_{2}$ has a higher Van't Hoff factor ( $\mathrm{i}=3$ ) than $\mathrm{NaCl}(\mathrm{i}=2)$, which is commonly used as the DS solute. The higher Van't Hoff factor would increase the osmotic pressure, which is the driving force, and finally increase the water flux. The water flux in membrane HTI-NW achieved $7.55-9.61 \mathrm{~L} / \mathrm{m}^{2} \cdot \mathrm{hr}$ and in membrane HTI-ES, it exceeds $13.58-15.10 \mathrm{~L} / \mathrm{m}^{2} \cdot \mathrm{hr}$. These findings indicate that the membrane morphologies affect the water flux. Membrane HTI-ES resulted higher water flux than membrane HTI-NW, which were likely to be affected by the porous condition of active layer and support layer. The active layer of membrane HTI-NW appears to be thicker, smooth and less porous (Figure 3(a) and Figure 3(c)), resulting in lower water flux than in case of membrane HTI-ES (Figure 4(a) and Figure 4(c)). The lower water flux as indicated in HTI-NW membrane is likely related to higher possibility of the occurrence of concentration polarization. The nonlinear dependence of flux on osmotic pressure investigated in FO mode is primarily a result of internal concentration polarization [24]. The concentrated FS coupled rapid permeation to DS caused diluted internal concentration polarization at the membrane interface in the support layer [25]. This occurs when the difference in concentration across the active layer of the membrane varies from the difference in concentration in the DS [18]. The porous support layer contributes to the internal concentration polarization [19], along with thickness, porosity, and tortuosity. The internal concentration polarization depends on the diffusion coefficient and on the membrane support layer [18]. 


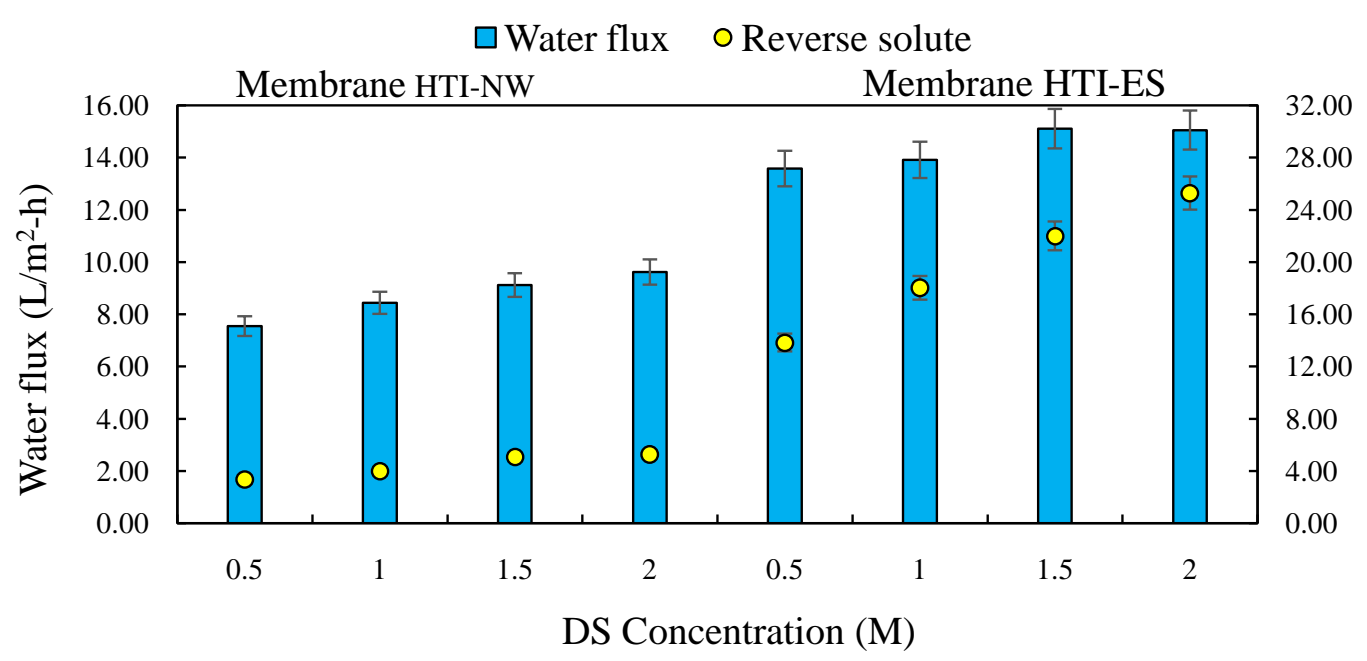

Figure 5. Water flux and reverse solute based on variation of DS $\mathrm{MgCl}_{2}$ concentration at $0.5 \mathrm{M}, 1 \mathrm{M}, 1.5 \mathrm{M}$ and $2 \mathrm{M}$ using membrane HTI-NW and HTI-ES. Experiment conditions: cross flow velocity $0.25 \mathrm{~m} / \mathrm{s}$, temperature $25^{\circ} \mathrm{C} \pm$ $1.0^{\circ} \mathrm{C}$.

When the concentration difference between FS and DS increases, the water flux, along with the reverse solute flux, increases as explained in Equation (6). In the FO process, the reverse movement of the solute from the DS to the FS through the membrane is unavoidable. This is because of the difference of concentrations [2]. In this study, the reverse solute flux rate reached $3.38-5.26 \mathrm{~g} / \mathrm{m}^{2}-\mathrm{hr}$ in membrane HTI-NW and increased considerably to $13.84-25.29 \mathrm{~g} / \mathrm{m}^{2}-\mathrm{hr}$ in membrane HTI-ES. The morphologies of the support layer of the membrane that faces the DS affected the reverse solute flux. The support layer with high resistance of the solute to diffusion will result in low reverse solute flux. Figure 3(b) is the SEM image of the support layer of membrane HTI-NW, in which the tortuosity seems higher and less porous, which makes it more capable of restraining the reverse solute flux, as compared to membrane HTI-ES (Figure 4(b)). The resistance of the solute to the diffusion within the membrane support layer explained the lower reverse solute flux in case of high tortuosity and less porous of membrane HTI-NW as compared to HTI-ES, which is characterized by lower tortuosity and higher porosity.

The investigation of reverse solute (Figure 6) was measured by monitoring increasing FS conductivity for $\mathrm{MgCl}_{2}$ and through ICP for individual $\mathrm{Mg}^{2+}$ ion and argentometric method for individual $\mathrm{Cl}^{-}$ion. The result indicated that concentration of $\mathrm{DS} \mathrm{MgCl}_{2}$ less affect to reverse solute of membrane HTI-NW than membrane HTI-ES. The reverse solute in membrane HTI-NW seemly constant along all concentration of DS $\mathrm{MgCl}_{2}$. The $\mathrm{Cl}^{-}$ion diffusion slightly higher than $\mathrm{Mg}^{2+}$ ion. In membrane HTI-ES, the reverse solute of $\mathrm{Cl}^{-}$ion was almost three times that of $\mathrm{Mg}^{2+}$ ion.

Coday et al. (2013), in their research using $\mathrm{NaCl}$ as DS, resulted reverse salt of $\mathrm{Na}^{+}$ion was higher than that of $\mathrm{Cl}^{-}$ion in TFC membrane and in the contrary, $\mathrm{Cl}^{-}$ion higher diffuse than $\mathrm{Na}^{+}$ion in CTA membrane [23]. This phenomenon possible to occurred due to $\mathrm{Na}^{+}$and $\mathrm{Cl}^{-}$ions were nearly equimolar [24] resulted similar diffusion constant, thereby difficult to differentiate the dominant effect, whether $\mathrm{Na}^{+}$or $\mathrm{Cl}^{-}$ions. Xue et al. (2015) using synthetic seawater as DS, resulted nutrient retention mostly achieved high retention $60 \%-90 \%$ and only TFC membrane give negative result for ammonium retention. The hypothesis to explain the negative result are greater ammonium permeability to TFC membrane and high negative zeta potential of TFC membrane that similar level to that of a cation exchange membrane [16] [26]. The other possibility is complex composition of seawater that not as effective as a $\mathrm{NaCl}$ solution as DS [27]. The use single DS such as $\mathrm{MgCl}_{2}$ with high osmotic pressure potential seemly promising especially to reject charge ion such nutrient ions $\mathrm{NO}_{2}^{-}, \mathrm{NO}_{3}^{-}, \mathrm{NH}_{4}^{+}$and $\mathrm{PO}_{4}^{3-}$ due to predictable dominant ion in rejection mechanism.

\section{Conclusions}

The rejection of nitrogen $\left(\mathrm{NO}_{2}, \mathrm{NO}_{3}\right.$, and $\left.\mathrm{NH}_{4}\right)$ and phosphorus $\left(\mathrm{PO}_{4}\right)$ nutrients can be achieved mostly more $95 \%$ by using $\mathrm{MgCl}_{2} 2 \mathrm{M}$ in the FO process. The concentration difference between the dissociated ions of $\mathrm{MgCl}_{2}$ in the DS plays a significant role in rejecting ion nutrients in the FS by the Donnan potential effect in low 


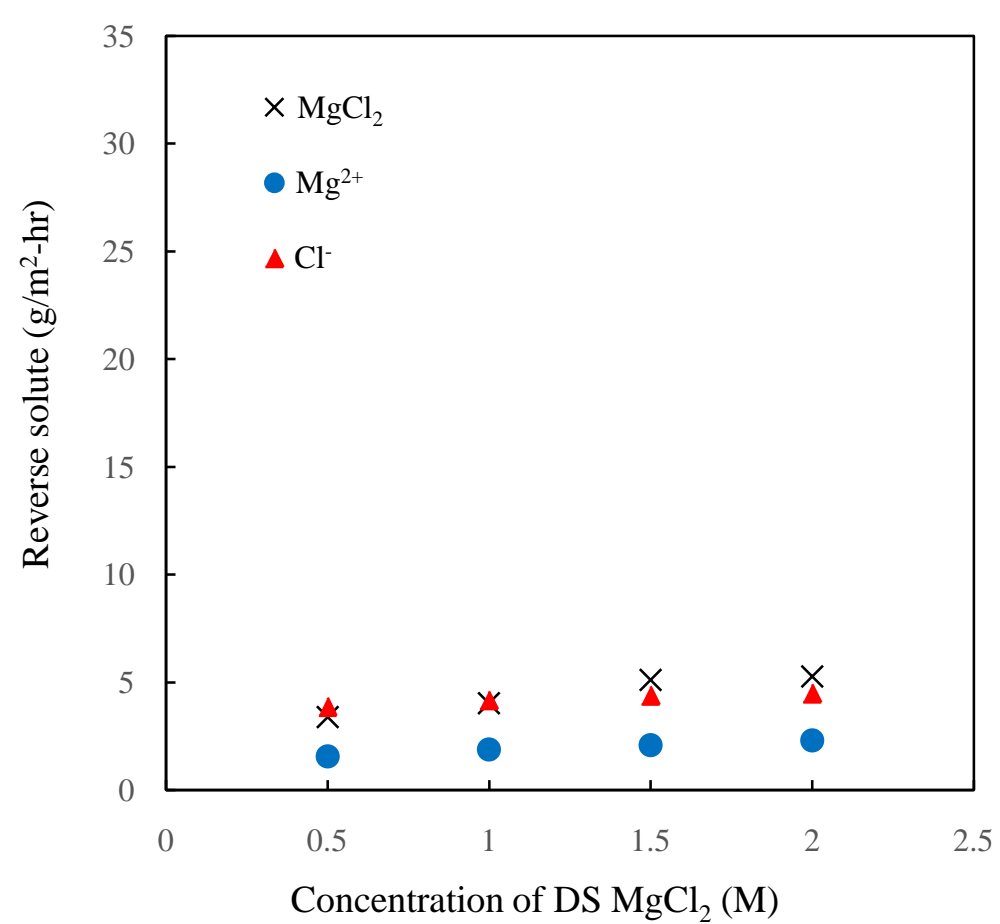

(a)

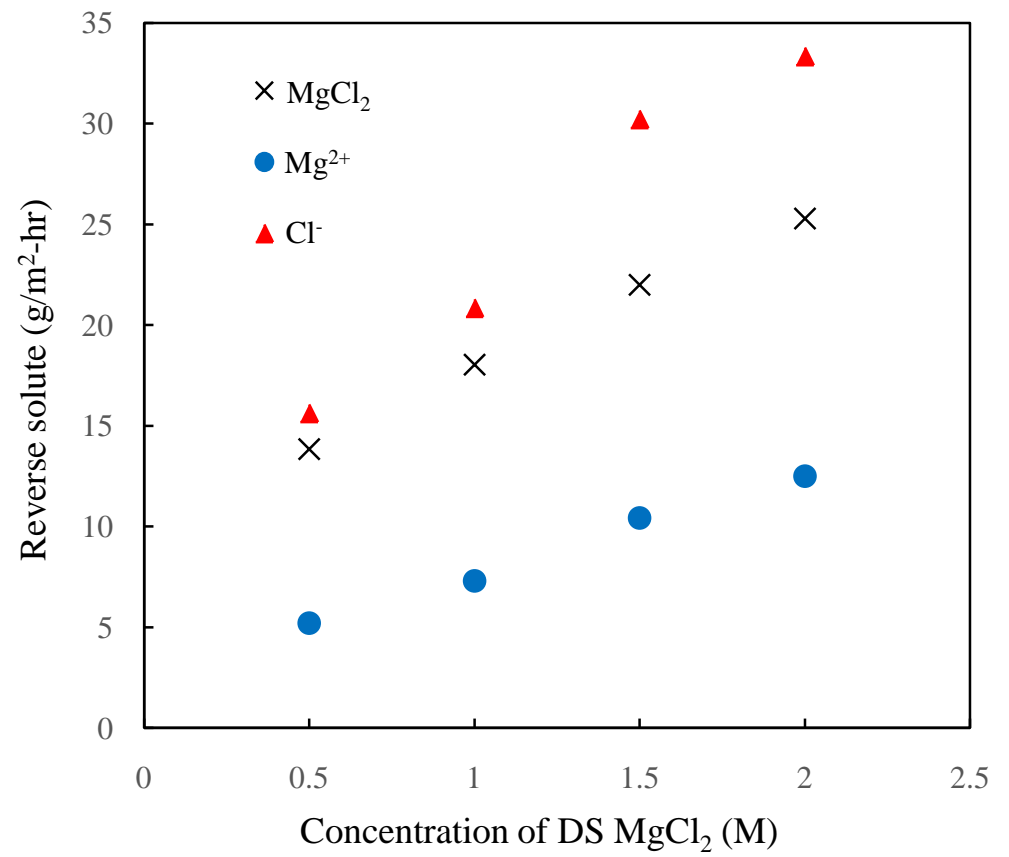

(b)

Figure 6. Reverse solute based on investigation $\mathrm{MgCl}_{2}$ (conductivity meter), ion $\mathrm{Mg}^{2+}$ (ICP), and ion $\mathrm{Cl}^{-}$(argentometric method) on HTI-NW and HTI-ES membranes. Experiment conditions: cross flow velocity $0.25 \mathrm{~m} / \mathrm{s}$, temperature $25 \pm 1.0$. (a) Membrane HTI-NW; (b) Membrane HTI-ES.

concentrations DS and by diffusion constant in high concentrations. Interestingly, using $\mathrm{MgCl}_{2}$ as $\mathrm{DS}$, the $\mathrm{Cl}^{-}$ ion is more dominantly to diffuse from DS to FS. The $\mathrm{Cl}^{-}$ion diffusion is slightly higher than $\mathrm{Mg}^{2+}$ ion diffusion in membrane HTI-NW, and almost three times than that in membrane HTI-ES. These conditions resulted in high rejection for anion nutrients due to electrostatic repulsion and cation nutrient due to attractions of water and $\mathrm{Cl}^{-}$ion. 
The increasing concentration difference between FS and DS generates higher water flux and reverse solute flux, and lower water flux and reverse solute flux on membrane HTI-NW as compared to HTI-ES. However, these studies are limited by the operation time that not only investigates further about the efficiency of FO in long periods. Future experiments should assess the long-time operation or compare nutrient rejection for other dissociated ionic DS.

\section{Acknowledgements}

We would like to acknowledge the Yamaguchi University for supporting and providing the facilities for our study. The first author is grateful to the Directorate General of Higher Education, Ministry of Education and Culture, Indonesia for the financial grant.

\section{References}

[1] Cath, T.Y., Childress, A.E. and Elimelech, M. (2006) Forward Osmosis: Principles, Applications, and Recent Developments. Journal of Membrane Science, 281, 70-87. http://dx.doi.org/10.1016/j.memsci.2006.05.048

[2] Lutchmiah, K., Verliefde, A.R.D., Roest, K., Rietveld, L.C. and Cornelissen, E.R. (2014) Forward Osmosis for Application in Wastewater Treatment: A Review. Water Research, 58, 179-197. http://dx.doi.org/10.1016/j.watres.2014.03.045

[3] Zhao, S., Zou, L., Tang, C.Y. and Mulcahy, D. (2012) Recent Development in Forward Osmosis: Opportunities and Challenges. Journal of Membrane Science, 396, 1-21. http://dx.doi.org/10.1016/j.memsci.2011.12.023

[4] Wei, J., Qiu, C., Tang, C.Y., Wang, R. and Fane, A.G. (2011) Synthesis and Characterization of Flat-Sheet Thin Film Composite Forward Osmosis Membranes. Journal of Membrane Science, 372, 292-302. http://dx.doi.org/10.1016/j.memsci.2011.02.013

[5] Ge, Q., Ling, M. and Chung, T.-S. (2013) Draw Solutions for Forward Osmosis Processes: Development, Challenges, and Prospects for the Future. Journal of Membrane Science, 47, 2386-2393. http://dx.doi.org/10.1016/j.memsci.2013.03.046

[6] Achilli, A., Cath, T.Y. and Childress, A.E. (2010) Selection of Inorganic-Based Draw Solution for Forward Osmosis Applications. Journal of Membrane Science, 364, 233-241. http://dx.doi.org/10.1016/j.memsci.2010.08.010

[7] Ji, D., Xi, B., Su, J., Huo, S., He, L., Liu, H. and Yang, Q. (2013) A Model to Determine the Lake Nutrient Standards for Drinking Water Sources in Yunnan-Guizhou Plateu Ecoregion, China. Journal of Environmental Sciences, 25, 1773-1783. http://dx.doi.org/10.1016/S1001-0742(12)60184-3

[8] Yang, Q., Wang, K.Y. and Chung, T.S. (2009) Dual Layer Hollow Fibers with Enhanced Flux as Novel Forward Osmosis Membranes for Water Production. Environmental Science Technology, 43, 2800-2805. http://dx.doi.org/10.1021/es803360t

[9] Saren, Q., Qiu, C.Q. and Tang, C.Y. (2011) Synthesis and Characterization of Novel Forward Osmosis Membrane Based on Layer-by-Layer Assembly. Environmental Science Technology, 45, 5201-5208. http://dx.doi.org/10.1021/es200115w

[10] Qiu, C., Qi, S. and Tang, C.Y. (2011) Synthesis of High Flux Forward Osmosis Membranes by Chemically Crosslinked Layer-by-Layer Polyelectrolytes. Journal of Membrane Science, 381, 74-80. http://dx.doi.org/10.1016/j.memsci.2011.07.013

[11] Qiu, C.Q., Setiawan, L., Wang, R., Tang, C.Y. and Fane, A.G. (2012) High Performance Flat Sheet Forward Osmosis Membrane with an NF-Like Selective Layer on a Woven Fabric Embedded Substrate. Desalination, 287, 266-270. http://dx.doi.org/10.1016/j.desal.2011.06.047

[12] Lee, S., Boo, C., Elimelech, M. and Hong, S. (2008) Comparison of Fouling Behavior in Forward Osmosis (FO) and Reverse Osmosis (RO). Journal of Membrane Science, 365, 34-39.

[13] Lay, W.C.L., Chong, T.H., Tang, C.Y., Fane, A.G., Zhang, J. and Liu, Y. (2010) Fouling Propensity of Forward Osmosis: Investigation of the Slower Flux Decline Phenomenon. Water Science \& Technology, 61, 927-936. http://dx.doi.org/10.2166/wst.2010.835

[14] Cath, T.Y., Hancock, N.T., Lundin, C.D., Jones, C.H. and Drewes, J.E. (2010) A Multi-Barrier Osmotic Dilution Process for Simultaneous Desalination and Purification of Impaired Water. Journal of Membrane Science, 362, 417426. http://dx.doi.org/10.1016/j.memsci.2010.06.056

[15] Holloway, R.W., Childress, A.E., Dennett, K.E. and Cath, T.Y. (2007) Forward Osmosis for Concentration of Anaerobic Digester Centrate. Water Research, 41, 4005-4014. http://dx.doi.org/10.1016/j.watres.2007.05.054

[16] Xue, W., Tobino, T., Nakajima, F. and Yamamoto, K. (2015) Seawater-Driven Forward Osmosis for Enriching Nitro- 
gen and Phosphorous in Treated Municipal Wastewater: Effect of Membrane Properties and Feed Solution Chemistry. Water Research, 69, 120-130. http://dx.doi.org/10.1016/j.watres.2014.11.007

[17] American Public Health Association (APHA), American Water Works Association (AWWA) and Water Environment Federation (WEF) (1998) Standard Method for the Examination of Water and Wastewater. 20th Edition, American Public Health Association, Washington DC.

[18] Cath, T.Y., Drewes, J.E. and Lundin, C.D. (2009) A Novel Hybrid Forward Osmosis Process for Drinking Water Augmentation Using Impaired Water and Saline Water Sources. WERC Consortium for Environmental Education and Technology Development at New Mexico State University and Water Research Foundation.

[19] McCutcheon, J.R., McGinnis, R.L. and Elimelech, M. (2006) Desalination by Ammonia-Carbon Dioxide Forward Osmosis: Influence of Draw and Feed Solution Concentrations on Process Performance. Journal of Membrane Science, 278, 114-123. http://dx.doi.org/10.1016/j.memsci.2005.10.048

[20] Yip, N.Y., Tiraferri, A., Phillip, W.A., Schiffman, J.D. and Elimelech, M. (2010) High Performance Thin-Film Composite Forward Osmosis Membrane. Environmental Science \& Technology, 44, 3812-3818. http://dx.doi.org/10.1021/es1002555

[21] Nguyen, T.P.N., Yun, E.T., Kim, I.C. and Kwon, Y.N. (2013) Preparation of Cellulose Triacetate/Cellulose Acetate (CTA/CA)-Based Membranes for Forward Osmosis. Journal of Membrane Science, 433, 49-49. http://dx.doi.org/10.1016/j.memsci.2013.01.027

[22] Bian, L.X., Fang, Y.Y. and Wang, X.L. (2014) Experimental Investigation into the Transmembrane Electrical Potential of the Forward Osmosis Membrane Process in Electrolyte Solutions. Membrane, 4, 275-286. http://dx.doi.org/10.3390/membranes4020275

[23] Coday, B.D., Heil, D.M., Xu, P. and Cath, T.Y. (2013) Effects of Transmembrane Hydraulic Pressure on Performance Forward Osmosis Membranes. Environmental Science \& Technology, 47, 2386-2393. http://dx.doi.org/10.1021/es304519p

[24] Phillip, W.A., Yong, J.S. and Elimelech, M. (2010) Reverse Draw Solute Permeation in Forward Osmosis: Modeling and Experiments. Environmental Science \& Technology, 44, 5170-5176. http://dx.doi.org/10.1021/es100901n

[25] Wang, Z.W., Tang, J.X., Zhu, C.W., Dong, Y., Wang, Q.Y. and Wu, Z.C. (2015) Chemical Cleaning Protocols for Thin Film Composite (TFC) Polyamide Forward Osmosis Membranes Used for Municipal Wastewater Treatment. Journal of Membrane Science, 475, 184-192. http://dx.doi.org/10.1016/j.memsci.2014.10.032

[26] Xie, H., Saito, T. and Hickner, M.A. (2011) Zeta Potential of Ion-Conductive Membranes by Streaming Current Measurement. Langmuir, 27, 4721-4727.

[27] Zhang, F., Brastad, K.S. and He, Z. (2011) Integrating Forward Osmosis into Microbial Fuel Cells for Wastewater Treatment, Water Extraction and Bioelectricity Generation. Environmental Science \& Technology, 45, 6690-6696. http://dx.doi.org/10.1021/es201505t 